\title{
Mineração
}

\section{Célula de carga de impacto na caracterização de materiais para a cominuição. Parte 2: Fratura de partículas}

\author{
Luís Marcelo M. Tavares \\ Laboratório de Tecnologia Mineral \\ Programa de Engenharia Metalúrgica e de Materiais, COPPE/UFRJ \\ E-mail: tavares@ufrj.br \\ Alfredo da Silva Lima \\ Laboratório de Tecnologia Mineral \\ Programa de Engenharia Metalúrgica e de Materiais, COPPE/UFRJ \\ E-mail:lima@metalmat.ufr.br
}

\section{Resumo}

As células de carga de impacto são usadas no cálculo de parâmetros importantes que caracterizam a deformação e a fratura de partículas individuais, incluindo a resistência, a energia específica de fratura e a rigidez de partícula. Nessa segunda parte do artigo, é analisada a influência da velocidade de impacto e do teor de umidade nas medidas. É demonstrado que as células de carga de impacto do LTM/COPPE permitem obter resultados consistentes de fratura de partículas em um intervalo amplo de tamanhos de interesse na cominuição.

Palavras-chave: impacto, fratura de partículas, cominuição.

\begin{abstract}
Impact load cells are used in calculating important parameters that characterize deformation and fracture behavior of individual particles, which include particle strength, particle fracture energy and particle stiffness. In this second part of the paper the influences of impact velocity and moisture content are analyzed. It is demonstrated that the impact load cells available at LTM/COPPE make it possible to obtain consistent particle fracture data over a wide range of sizes of interest in comminution.
\end{abstract}

Keywords: impact, particle fracture, comminution. 


\section{Introdução}

Na primeira parte desse trabalho[1], foi apresentada a descrição da célula de carga de impacto, bem como os resultados de calibração que demonstram que o aparelho é capaz de medir precisamente forças e deformações que partículas sofrem durante o carregamento rápido.

Nessa segunda parte do trabalho, é analisada a aplicação da célula de carga de impacto (CCI) no estudo da fratura de partículas, avaliando-se a influência da velocidade de carregamento e do teor de umidade nos resultados obtidos. É demonstrado que as diferentes resoluções e energias de impacto atingidas nas barras usadas na COPPE permitem que resultados consistentes de fratura em um amplo intervalo de tamanhos de partículas sejam obtidos.

\section{Parâmetros de fratura de partículas}

A curva de força-tempo medida no ensaio na CCI descreve a história do carregamento da partícula (Figura 1), sendo usada para avaliar o comportamento da partícula durante todo o evento de impacto, que, normalmente, dura menos que 2 milissegundos. A perda da integridade da partícula (ruptura) normalmente corresponde à força mais alta (ponto $\mathrm{A}$ na figura). Após a ruptura (fratura primária), a força exercida sobre a partícula, normalmente, cai, até que a bola - ainda em queda - aplique esforços sobre os fragmentos, resultando em picos adicionais no gráfico, até que a esfera atinja a posição final de repouso (ponto C). A partir dessa curva é possível calcular alguns parâmetros relevantes das características de deformação e fratura de materiais particulados, como a rigidez, a energia específica de fratura e a resistência à tração.

A energia de fratura de uma partícula corresponde à energia de deformação armazenada na partícula até o instante de ruptura e corresponde à área abaixo da curva de forças $(F)$ em função das deformações, calculada a partir de

$$
E=\int_{0}^{\Delta_{c}} F d \Delta
$$

na qual $\Delta$ é a deformação da partícula e $\Delta_{c}$ é a deformação no instante de ruptura. Na prática, a CCI oferece uma expressão para a deformação total nas proximidades do contato. Substituindo $\alpha$ (obtida pela Equação 7 da primeira parte do artigo) por $\Delta$ na Equação (1), tem-se

$$
E=v_{o} \int_{0}^{t_{c}} F(\tau) d \tau+g \int_{0}^{t_{c}} F(\tau) \tau d \tau-\frac{1}{2 m_{b}}\left(\int_{0}^{t_{c}} F(\tau) d \tau\right)^{2}-\frac{1}{\rho A C} \int_{0}^{t_{c}} F^{2}(\tau) d \tau
$$

sendo que $v_{o}$ é a velocidade de impacto, $g$ é a aceleração da gravidade, $\rho$ é a densidade, $A$ é a área da seção transversal e $C$ é a velocidade de propagação da onda na barra, $m_{b}$ é a massa da bola, $t_{c}$ é o tempo da fratura primária da partícula. A energia específica de fratura é dada por $\mathrm{Em}=\mathrm{E} / \mathrm{mp}$, sendo $\mathrm{mp}$ a massa da partícula.

A Equação (2) também pode ser usada no cálculo da energia total absorvida pela partícula durante o impacto (também chamada de energia de cominuição). Nesse caso, $t_{c}$ deve ser substituído pelo tempo total transcorrido no impacto até a parada final do impactor.

A resistência de uma partícula de formato irregular não pode ser definida inequivocamente, uma vez que o seu estado interno de tensões não é conhecido $a$ priori e nem pode ser facilmente calculado. Entretanto uma expressão proposta por Hiramatsu e Oka [2] oferece uma boa aproximação para a resistência à tração da partícula (considerando-a esférica) [3],

$$
\sigma_{p}=\frac{2,8 F_{c}}{\pi d_{p}^{2}}
$$

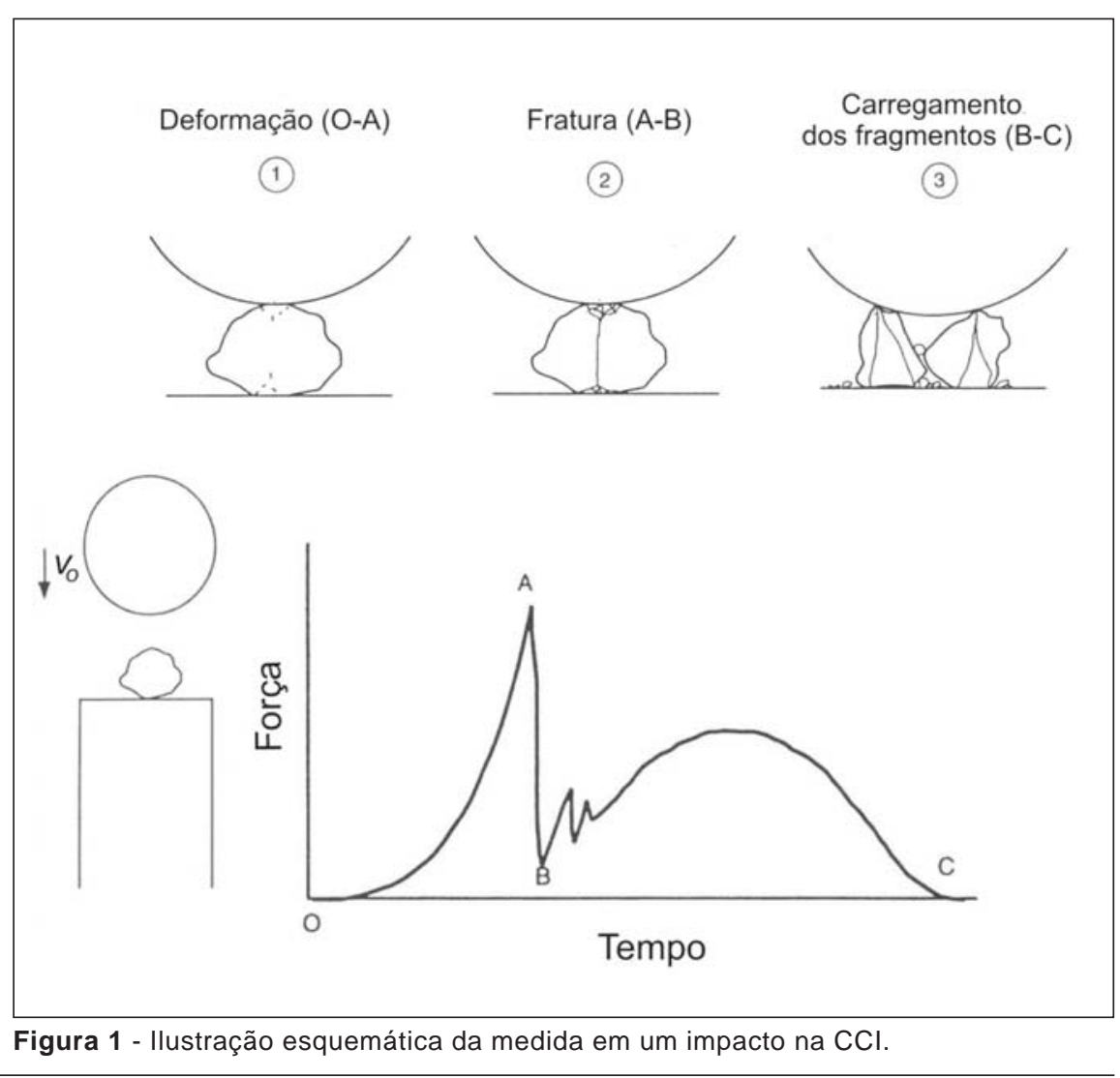


sendo quw $F_{c}$ é a força responsável pela fratura da partícula e $d_{p}$ é a distância entre os pontos de carregamento. Por conveniência, $d_{p}$, na Equação (3), é estimado como a média geométrica das peneiras nas quais o material testado é retido e passante.

A rigidez (stiffness) de uma partícula é determinada com base na teoria de contatos de Hertz, sendo dada por [3]:

$k_{p}=\frac{K k_{b}}{K-k_{b}}$

na qual $K=\left(0,576 \frac{F_{c}^{5}}{d_{p} E^{3}}\right)^{1 / 2}$

$k_{b}$ é a constante de rigidez da bola, que é a mesma da barra da CCI. Uma vez que os dois materiais são constituídos por aços, os módulos de elasticidade são aproximadamente iguais a $210 \mathrm{GPa}$. A razão de Poisson é aproximadamente igual a 0,29, então a rigidez do sistema bola/barra equivale a, aproximadamente, $230 \mathrm{GPa}$.

Substituindo a Equação (4) em (3), dado que $E_{m}=E /\left(\beta \rho_{p} d_{p}^{3}\right)$, na qual $\beta$ é o fator de forma e $\rho_{p}$ é a massa específica da partícula, tem-se, então,

$$
\sigma_{p}=K_{e}^{2 / 5}\left(E_{m} \beta \rho_{p}\right)^{3 / 5}
$$

A Equação (5) estabelece a relação entre as três medidas apresentadas nesse trabalho - a energia de fratura de partícula, a resistência à tração e a rigidez de uma forma independente do tamanho de partícula.

\section{Procedimento experimental}

As amostras dos testes foram selecionadas por peneiramento do material realizado em intervalos estreitos de tamanhos (compreendidos entre peneiras na série $\sqrt[4]{2}$ ), foram preparadas por peneiramento. Lotes contendo um mínimo de 30, tipicamente 50 partículas, foram preparados aleatoriamente para ensaios. Esse número significativo, superior àquele normalmente empregado em ensaios mecânicos, se deve, em parte, à grande variabilidade associada à forma das partículas.

O ensaio inicia com a escolha de uma energia de impacto adequada (pela combinação do peso do impactor e da altura de queda), a qual deve ser suficientemente alta para fraturar todas as partículas no lote, porém não excessiva, o que poderia dificultar (para alguns materiais) a identificação do ponto de fratura. A seguir, as partículas são individualmente pesadas e ensaiadas. O tempo compreendido entre o início do ensaio e o encerramento da análise dos resultados de um lote de 50 partículas pode variar de 2 a 3 horas.

\section{Resultados e discussão}

\subsection{Curva força-tempo e análise de variabilidade}

Um resultado típico de um ensaio de impacto é apresentado na Figura 2. Foi realizado usando a CCI de $63 \mathrm{~mm}$ sobre uma partícula de sienito da Pedrei- ra Vigné (RJ), com tamanho contido no intervalo de 45,0 por $37,5 \mathrm{~mm}$. A seta indica a fratura primária, que ocorre $74 \mu \mathrm{s}$ após o contato entre a esfera em queda e a partícula. Uma síntese dos resultados desse ensaio é apresentada na Tabela 1.

É importante destacar que nem todas as curvas força-deformação permitem a detecção direta da fratura primária quanto aquela apresentada na Figura 2. Freqüentemente muitos eventos de fratura podem ser observados em uma única curva. Assim, um certo grau de subjetividade freqüentemente é usado na definição do ponto da fratura primária. Quando esse ponto não pode ser detectado de forma satisfatória, o resultado do experimento é, então, rejeitado.

O resultado do cálculo da energia absorvida pela partícula ao longo do tempo (Equação 2) é apresentado na Figura 3 , que mostra que a energia de cominuição representou aproximadamente 93\% da energia aplicada. Valores altos como esses são característicos para vários materiais e para baixas energias de impacto [4]. A parte restante da energia de impacto é absorvida pela barra da CCI, ou, ainda, usada na restituição do impactor.

Tabela 1 - Síntese dos resultados da fratura de partícula de sienito da Figura 2.

\begin{tabular}{c|c|c|c}
\hline Parâmetro & Símbolo & Valor & Unidade \\
\hline Massa da partícula & $m_{p}$ & 143,2 & $\mathrm{~g}$ \\
\hline Tempo transcorrido até a fratura primária & $t_{c}$ & 74,0 & $\mu \mathrm{s}$ \\
\hline Tempo transcorrido até o final do impacto & $t_{f}$ & 1886 & $\mu \mathrm{s}$ \\
\hline Força crítica & $F_{c}$ & 29,6 & $\mathrm{kN}$ \\
\hline Resistência da partícula & $\sigma_{p}$ & 15,6 & $\mathrm{MPa}$ \\
\hline Energia de impacto & $E_{i}$ & 57,2 & $\mathrm{~J}$ \\
\hline Energia de fratura & $E$ & 3,725 & $\mathrm{~J}$ \\
\hline Energia de fratura específica & $E_{m}$ & 26,01 & $\mathrm{~J} / \mathrm{kg}$ \\
\hline Rigidez & $k_{p}$ & 120,8 & $\mathrm{GPa}$ \\
\hline Energia de cominuição & $E_{c}$ & 53,4 & $\mathrm{~J}$ \\
\hline
\end{tabular}

REM: R. Esc. Minas, Ouro Preto, 59(2): 165-172, abr. jun. 2006 
Parâmetros de fratura de partículas geralmente apresentam uma grande variabilidade, a qual deve ser descrita estatisticamente. Essa variabilidade é influenciada pelos diferentes formatos de partícula na amostra, mas ela é, principalmente, determinada pela distribuição de tamanhos de defeitos, anisotropia, etc. O procedimento normalmente adotado na descrição dessa variabilidade consiste, inicialmente, da ordenação dos resultados experimentais de forma ascendente, atribuindo os índices $i=1,2, \ldots, N$ a cada uma das observações, onde $N$ é o número total de partículas ensaiadas. Para a distribuição de energias específicas de fratura, os percentis são geralmente estimados por

$P\left(E_{m, i}\right)=(i-0,5) / N$

A seguir, os pares resultantes $\left[E_{m, i}\right.$; $\left.P\left(E_{m, i}\right)\right]$ são ajustados a uma distribuição estatística apropriada, a fim de permitir a extração das estatísticas relevantes da amostra, como a média e a variância. A distribuição de probabilidade que tem freqüentemente apresentado os melhores resultados na descrição de resultados de testes com a CCI é a log-normal [3], que, no caso da distribuição de energias específicas de fratura, é dada por

$P\left(E_{m}\right)=\frac{1}{2}\left[1+\operatorname{erf}\left(\frac{\ln E_{m}-\ln E_{m, 50}}{\sqrt{2 \sigma_{E}^{2}}}\right)\right]$ (7)

na qual $\ln E_{m, 50}$ e $\sigma_{E}^{2}$ representam a média e a variância da distribuição, respectivamente.

A Figura 4 compara os resultados de energia específica de fratura de diferentes tamanhos, lançados em escala de probabilidade, junto à linha que caracteriza o ajuste à distribuição log-normal. Uma distribuição que também tem encontrado alguma aplicação na representação de resultados da CCI é a de Weibull [5].

\subsection{Efeito do tamanho de partícula}

Conforme é ilustrado na Figura 4, os parâmetros de fratura são significati-

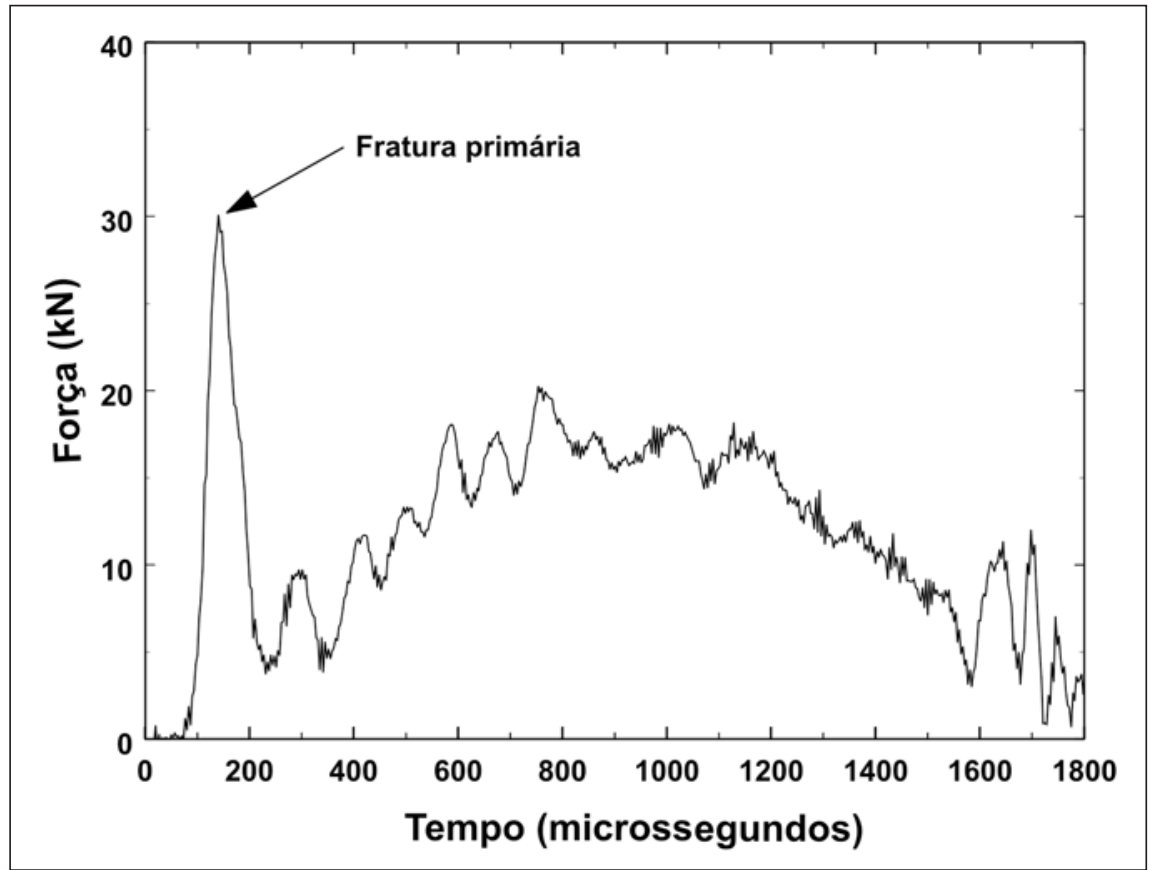

Figura 2 - Resultado de ensaio de impacto na $\mathrm{CCl}$ de $63 \mathrm{~mm}$ com partícula de rocha da Pedreira Vigné (RJ) de granulometria de 45,0×37,5 mm. Impacto com bola de 4,6 $\mathrm{kg} \mathrm{a}$ partir de uma altura de queda de $1,31 \mathrm{~m}$.

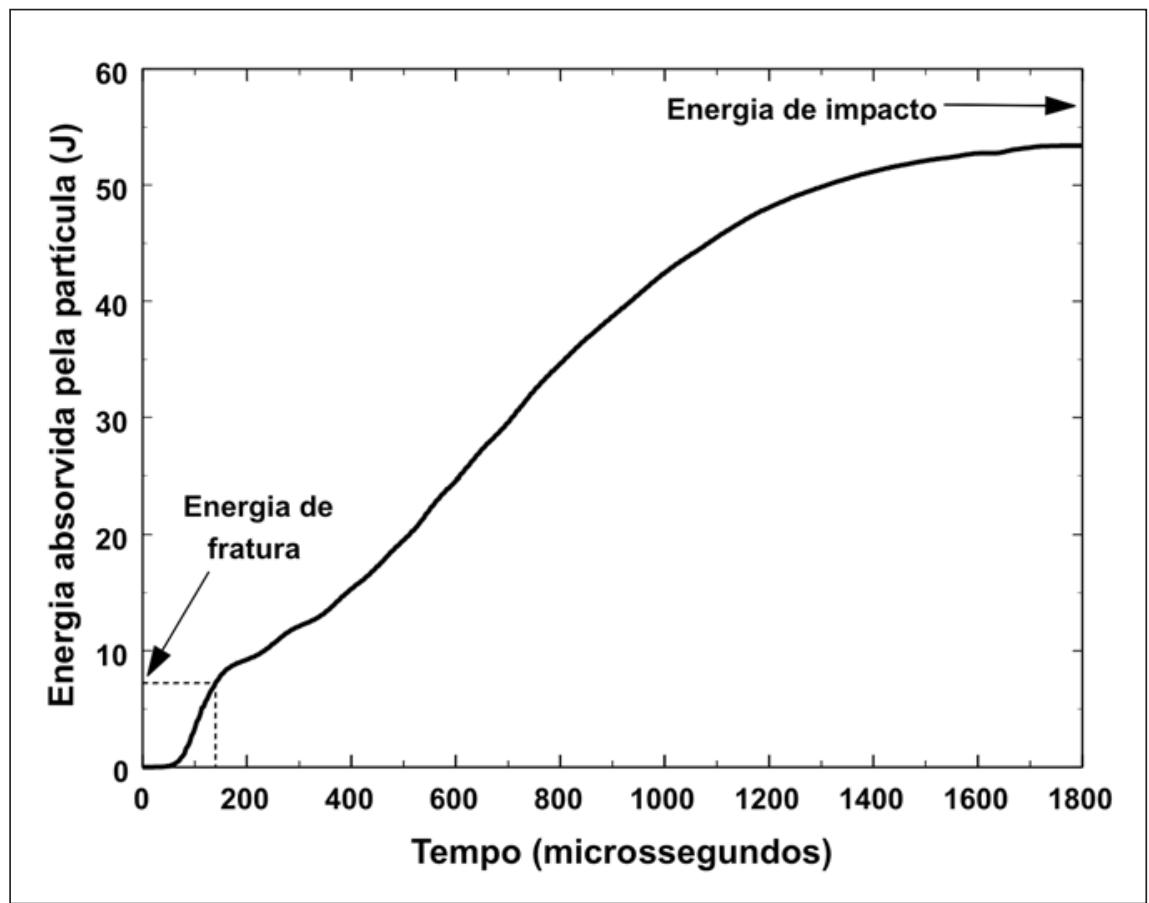

Figura 3 - Energia absorvida pela partícula da Figura 2 durante o impacto.

vamente influenciados pelo tamanho de partícula. Uma síntese das medidas de energia de fratura é apresentada na Figura 5, mostrando os valores de média e intervalo de confiança de $90 \%$ na forma de barras de erro. Essas barras indicam a magnitude da variabilidade dos parâme- tros fratura, que mostram que os valores variam por mais de uma ordem de magnitude. A Figura 5 mostra que ocorre um aumento significativo da energia específica de fratura à medida que diminui o tamanho de partícula, particularmente abaixo de, aproximadamente, $1 \mathrm{~mm}$. A 
Luís Marcelo M. Tavares et al.

mesma tendência também foi observada para os dados de resistência de partícula. Analogamente, a Figura 6 mostra os resultados de resistência de partícula.

A Figura 7 mostra a variação da rigidez de partícula com o tamanho de partícula. Nesse caso, observa-se que não existe uma influência clara do tamanho de partícula. Esse mesmo comportamento é observado para uma variedade de materiais [3].

\subsection{Efeito da velocidade de impacto}

Em um estudo anterior [3], foi demonstrado que as medidas de energia de fratura de materiais selecionados, realizadas no intervalo de velocidades de impacto de 0,3 a $1,7 \mathrm{~m} / \mathrm{s}$, eram aproximadamente independentes da velocidade de impacto. No presente trabalho, esse ponto é novamente analisado, tendo em vista o maior intervalo de velocidades atingido com as CCI instaladas no LTM/ COPPE (até $7 \mathrm{~m} / \mathrm{s}$ ). Adicionalmente, os resultados são ainda comparados àqueles obtidos em compressão lenta em uma prensa EMIC ${ }^{\oplus}$ com capacidade de $10 \mathrm{kN}$ e equipada com uma célula de carga de alta resolução a uma taxa de deformação de $10 \mathrm{~mm} / \mathrm{min}$ [6].

A Figura 8 mostra a influência da velocidade de impacto, $v_{o}$, na energia específica de fratura, que é pequena na faixa de velocidade estudada. Quando os resultados obtidos são comparados com os de compressão lenta (Tabela 2), observa-se uma variação significativa. Nesse caso, pode-se observar que, na CCI, as partículas se comportam de forma menos deformável (maiores valores de rigidez), exibindo resistência à fratura muito superior. Essa combinação faz com que energias de fratura, também maiores, porém não muito, fossem obtidas com a CCI.

De fato, tem sido amplamente reportado na literatura que a resistência dinâmica de materiais geológicos é significativamente superior à resistência estática à tração [7]. Yashima et al. [8] estudaram a resposta de uma variedade

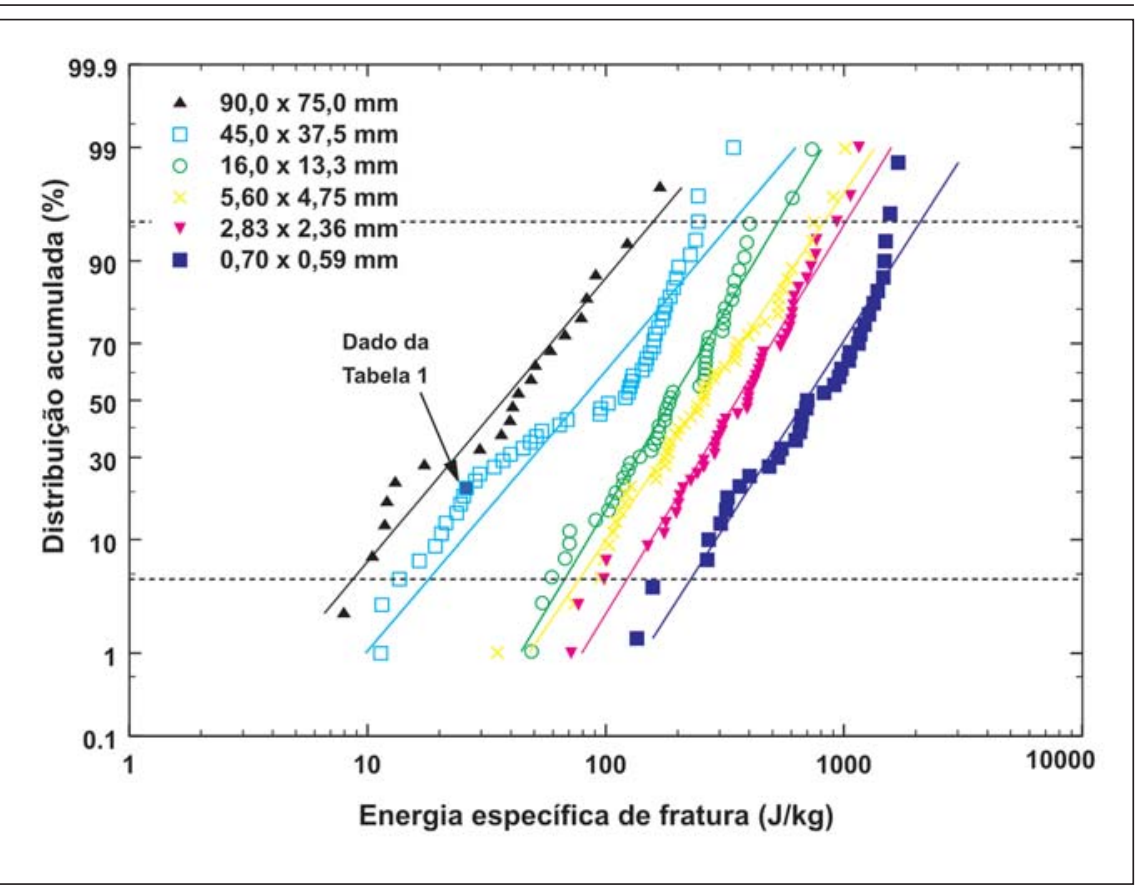

Figura 4 - Distribuição de energias de fratura de tamanhos selecionados de amostra de rocha da Pedreira Vigné (RJ), mostrando o intervalo de confiança de $90 \%$ (linhas pontilhadas).

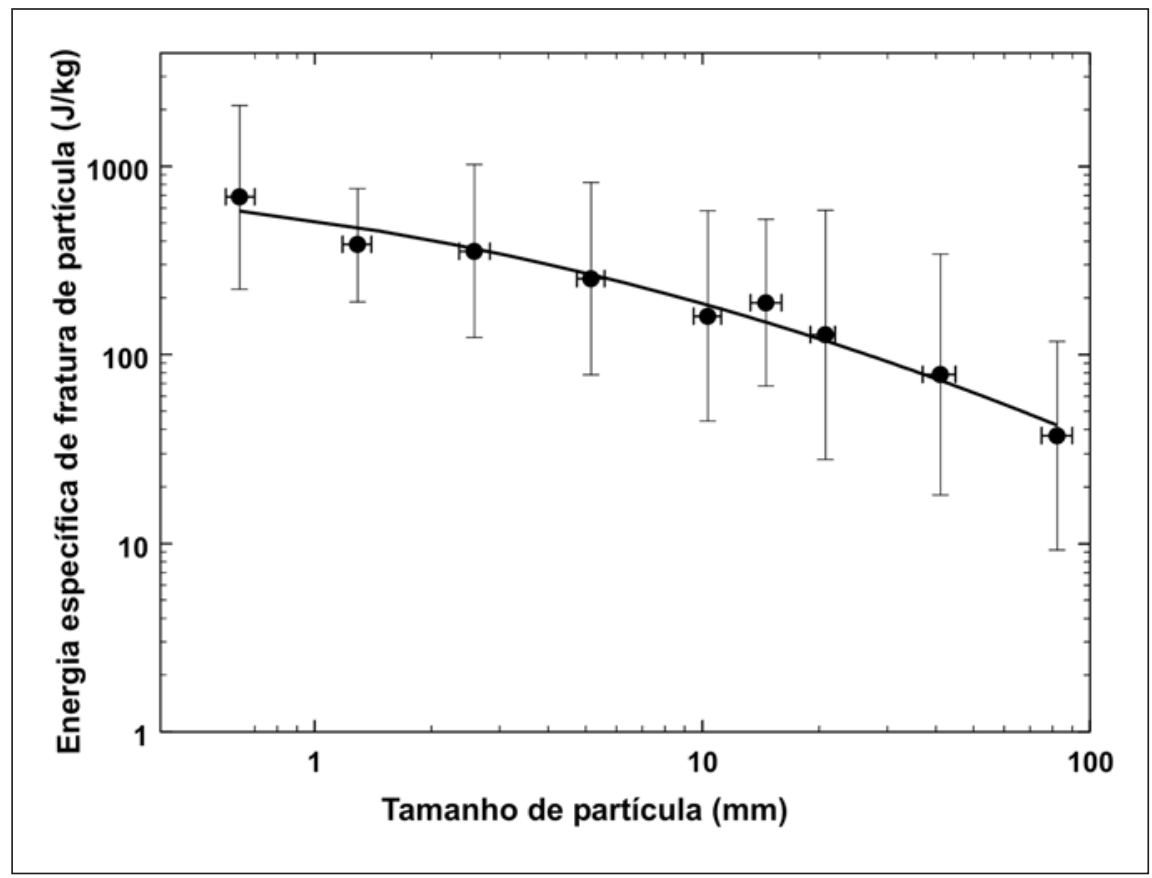

Figura 5 - Influência do tamanho de partícula na energia específica de fratura da amostra de rocha da Pedreira Vigné (RJ) (símbolos: medianas; barras de erro: intervalo de confiança de $90 \%)$.

de minerais com forma esférica a diferentes taxas de carregamento e observaram que, tanto o módulo de elasticidade, quanto a resistência, aumentavam com a taxa de carregamento. Entretanto, naquele estudo, foi observado que a energia específica de fratura se manteve relativamente constante. 


\subsection{Efeito da umidade do material}

Ensaios na CCI são realizados com amostras previamente secas. Na indústria, entretanto, é comum a cominuição de materiais contendo alguma umidade superficial, ou até imersos em água, como é o caso da moagem a úmido. Muito poucos são os estudos que analisam a influência do meio na fratura das partículas. Yashima et al. [9], por exemplo, observaram que, tanto a resistência de partícula, quanto a energia de fratura, diminuíam quando o meio muda de vácuo para ar e para água.

Experimentos foram realizados com a amostra de bauxita sob diferentes condições: seca, umedecida superficialmente pela imersão rápida em água imediatamente antes do ensaio e ensaiada após imersão pelo período de um dia. Uma síntese dos resultados de energia de fratura (base seca) é apresentada na Tabela 3. O aumento do teor de umidade observado foi muito significativo, provavelmente devido ao elevado grau de porosidade do material. A tabela mostra que o aumento do teor de umidade resulta em aumentos, tanto da resistência de partícula, quanto da energia de fratura. Esse aumento significativo, que contradiz os resultados de Yashima e colaboradores, pode ser explicado pelo efeito combinado da alta porosidade do material e do elevado percentual de materiais argilosos, que intensifica o comportamento plástico do minério, quando úmido.

Por fim, as CCI do LTM/COPPE têm sido utilizadas, com sucesso, na medida das propriedades mecânicas de uma variedade de materiais particulados, que incluem minérios, rochas, carvões, clínqueres de cimento e até granalhas usadas no corte de rochas ornamentais. A CCI também tem provado apresentar grande utilidade na análise do comportamento dinâmico de corpos-de-prova com formatos regulares (cilindros ou cubos), tendo, como exemplos, a avaliação da resistência ao impacto de cerâmicos a base de alumina [10] e de argamassas.

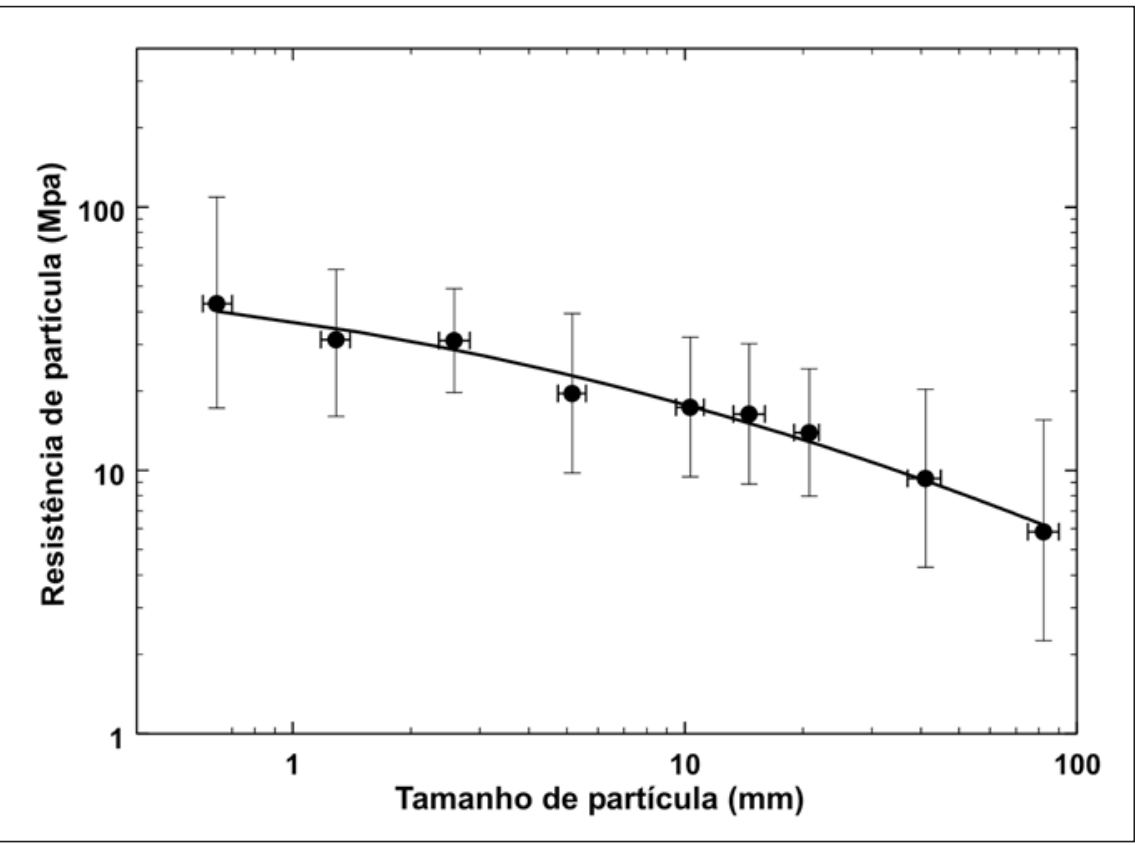

Figura 6 - Influência do tamanho de partícula na resistência de partícula da amostra de rocha da Pedreira Vigné (RJ) (símbolos: medianas; barras de erro: intervalo de confiança de $90 \%)$.

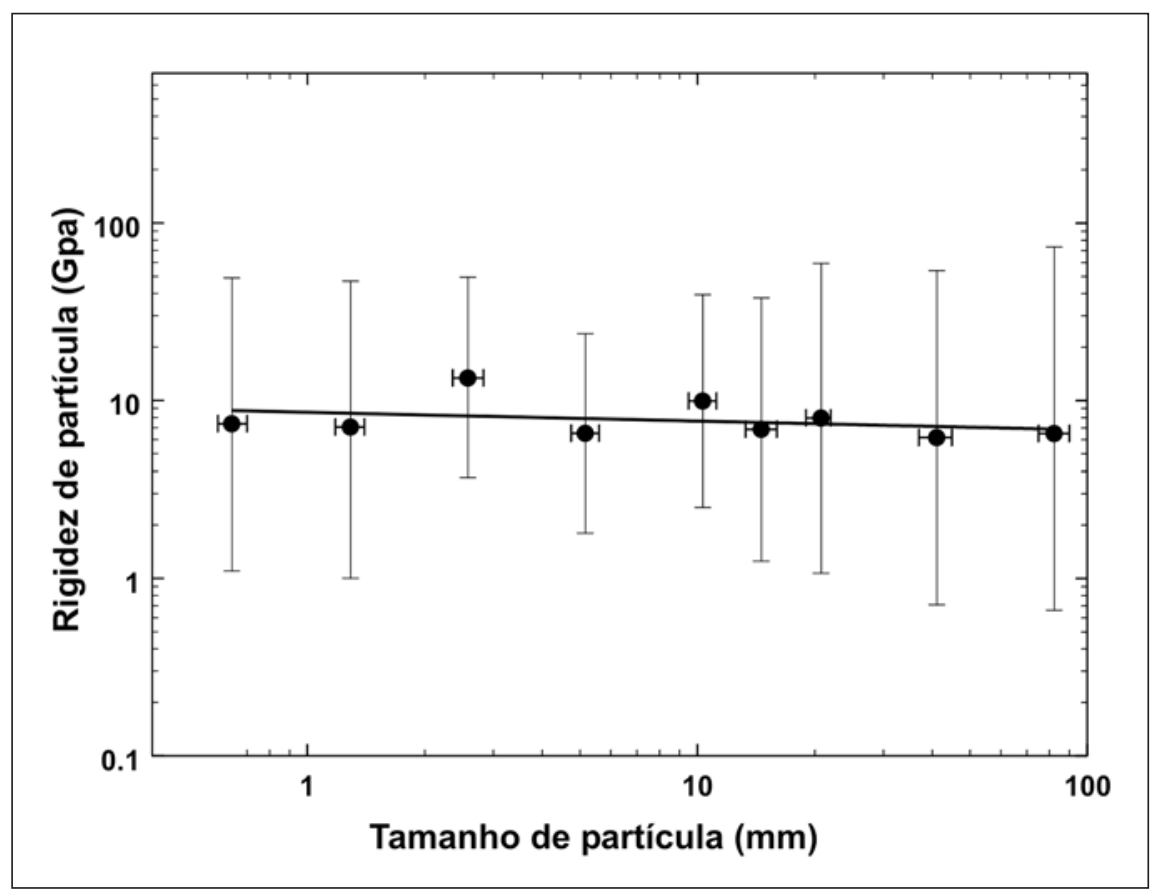

Figura 7 - Influência do tamanho de partícula na rigidez de partícula da amostra de rocha da Pedreira Vigné (RJ) (símbolos: medianas; barras de erro: intervalo de confiança de $90 \%)$.

\section{Conclusões}

Medidas de energias de fratura, resistência e rigidez de partículas contidas em um intervalo amplo de tamanhos, usando as diferentes células de carga disponíveis no LTM/COPPE, demonstram que resultados consistentes podem ser obtidos pela combinação das diferentes células de carga. Nessas medidas, observou-se o conhecido efeito do aumento da energia de fratura e da resis- 


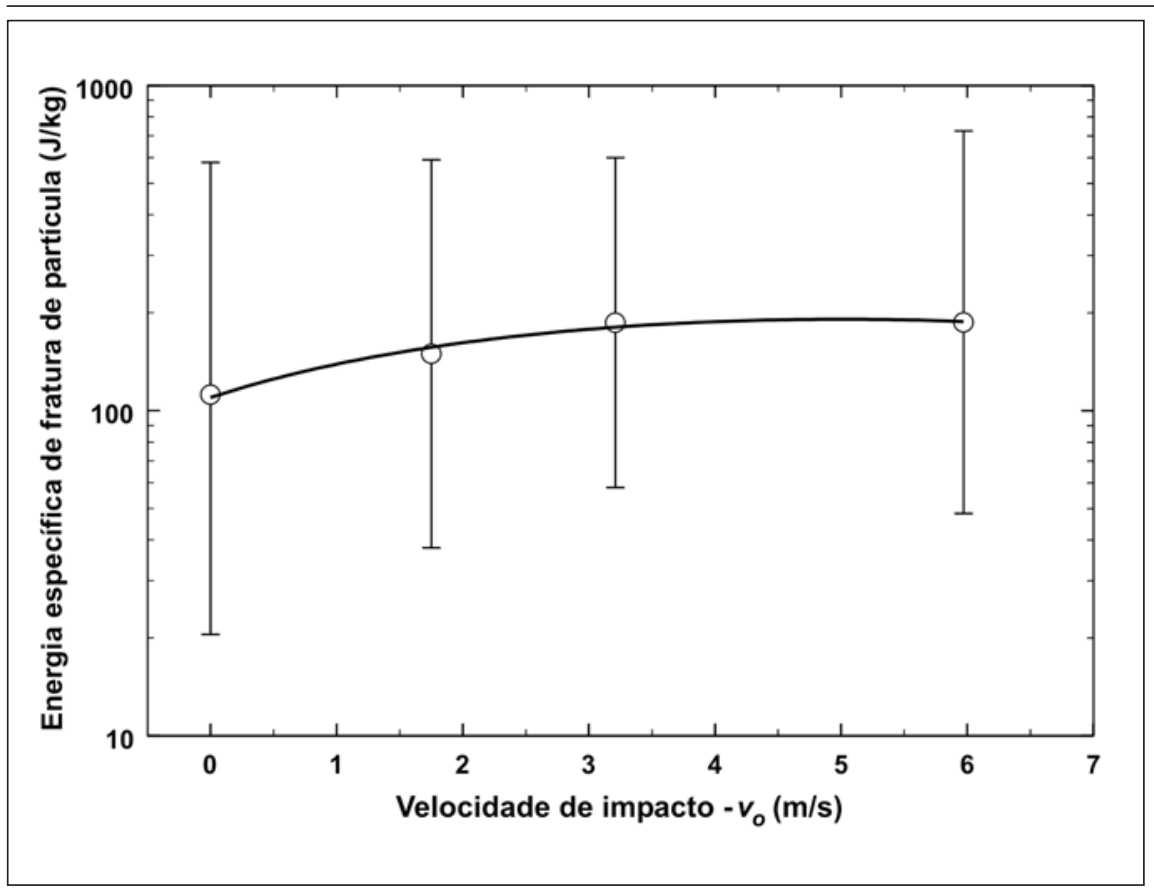

Figura 8 - Influência da velocidade de impacto na distribuição de energias de fratura (símbolos: medianas; barras de erro: intervalo de confiança de 90\%). tência com a diminuição do tamanho de partícula, enquanto a rigidez se manteve relativamente constante.

A influência da velocidade de impacto nos parâmetros de fratura não se mostrou significativa dentro do intervalo de um a vários metros por segundo. Por outro lado, a menor resistência observada com o carregamento lento demonstra que muito cuidado deve ser usado no emprego de informações de ensaios em prensas na previsão da cominuição em equipamentos de cominuição.

A análise do efeito da umidade nos parâmetros de fratura de uma amostra de bauxita mostrou que a energia de fratura e a resistência aumentam com o teor de umidade, o que deve também ser levado em consideração no projeto de equipamentos de cominuição, pelo menos para materiais como a bauxita analisada, que apresenta elevado grau de porosidade e presença de argilas.

Tabela 2 - Influência da velocidade de impacto nos parâmetros de fratura de amostra de bauxita (16,0x13,3 mm).

\begin{tabular}{|c|c|c|c|c|c|c|}
\hline \multirow{2}{*}{$\begin{array}{l}\text { Velocidade de } \\
\text { impacto }(\mathrm{m} / \mathrm{s})\end{array}$} & \multicolumn{2}{|c|}{$\begin{array}{l}\text { Energias específicas de } \\
\text { fratura }\end{array}$} & \multicolumn{2}{|c|}{ Resistência de partícula } & \multicolumn{2}{|c|}{ Rigidez de partícula } \\
\hline & $E_{m 50}(\mathrm{~J} / \mathrm{kg})$ & $\sigma_{E}^{2}$ & $\sigma_{\mathrm{p} 50}(\mathrm{MPa})$ & $\sigma_{\sigma}^{2}$ & $k_{p 50}(\mathrm{GPa})$ & $\sigma_{k}^{2}$ \\
\hline $0,0002^{*}$ & 112,1 & 1,020 & 5,23 & 0,369 & 0,92 & 0,914 \\
\hline 1,8 & 149,6 & 0,698 & 10,20 & 0,121 & 3,21 & 0,912 \\
\hline 3,2 & 186,7 & 0,504 & 9,58 & 0,140 & 2,46 & 0,500 \\
\hline 6,0 & 187,1 & 0,678 & 11,08 & 0,171 & 3,46 & 0,869 \\
\hline
\end{tabular}

* Ensaio de compressão lenta.

Tabela 3 - Influência do teor de umidade nos parâmetros de fratura de amostra de bauxita (16,0x13,3 mm) ensaiada a uma velocidade de queda de $3,2 \mathrm{~m} / \mathrm{s}$.

\begin{tabular}{|c|c|c|c|c|c|c|}
\hline \multirow{2}{*}{$\begin{array}{l}\text { Teor de umidade } \\
\qquad(\%)\end{array}$} & \multicolumn{2}{|c|}{$\begin{array}{l}\text { Energias específicas de } \\
\text { fratura }\end{array}$} & \multicolumn{2}{|c|}{ Resistência de partícula } & \multicolumn{2}{|c|}{ Rigidez de partícula } \\
\hline & $E_{m 50}(\mathrm{~J} / \mathrm{kg})$ & $\sigma_{E}^{2}$ & $\sigma_{\mathrm{p} 50}(\mathrm{MPa})$ & $\sigma_{\sigma}^{2}$ & $k_{p 50}(\mathrm{GPa})$ & $\sigma_{k}^{2}$ \\
\hline 0,0 & 186,7 & 0,504 & 9,58 & 0,140 & 2,46 & 0,500 \\
\hline 2,1 & 256,4 & 0,503 & 10,85 & 0,142 & 2,25 & 0,930 \\
\hline 8,1 & 269,1 & 0,602 & 11,66 & 0,140 & 2,10 & 1,193 \\
\hline
\end{tabular}




\section{Agradecimentos}

Os autores agradecem à FUJB, FAPERJ e CNPq pelo auxílio financeiro utilizado na construção das células de carga de impacto. Os autores agradecem também ao Prof. Tsuneharu Ogasawara pelo uso da prensa no ensaio de compressão.

\section{Referências bibliográficas}

1. TAVARES, L.M., LIMA, A.S. Célula de carga de impacto na caracterização de materiais para a cominuição. Parte 1: Calibração, REM: Revista da Escola de Minas, v. 59(1), p. 61-69, 2006.

2. HIRAMATSU, Y., OKA, Y. Determination of the tensile strength of rock by a compression test of an irregular test piece. International Journal of Rock Mechanics and Mining Sciences, v. 3, p. 89-99, 1966.

3. TAVARES, L.M., KING, R.P. Singleparticle fracture under impact loading. International Journal of Mineral Processing, v. 54, p. 1-28, 1998.

4. TAVARES, L.M. Energy absorbed in breakage of single particles in drop weight testing. Minerals Engineering, v. 12, p. 43-50.

5. TAVARES, L.M., CERQUEIRA, M.C. Statistical analysis of impact-fracture characteristics and microstructure of industrial Portland cement clinkers. Cement and Concrete Research, v.36, p.409-415.

6. LIMA, A. Calibração da célula de carga de impacto e aplicação na fratura de materiais particulados. Projeto de Formatura em Engenharia Metalúrgica, Escola Politécnica, UFRJ, 2005. 47p.
7. GRADY, D.E., KIPP, M.E. Dynamic rock fragmentation. In: ATKINSON, B.K (ed.). Fracture Mechanics of Rock. London: Academic, London, 1987. p.429-475.

8. YASHIMA, S., KANDA, Y., SAITO, F., SASAKI, T., IIJIMA, M. Mechanical properties of brittle materials and their single fracture under dynamic loads. Kagaku Kogaku, v. 37, p. 1218-1226, 1973.

9. YASHIMA, S., SAITO, F., MIKUNI, T. Effect of environmental water on singleparticle crushing. Kagaku Kogaku Ronbunshu, v. 2, p. 150-153, 1976.

10. CARDOSO, A. Caracterização dinâmica por impacto de cerâmicos à base de alumina. Departamento de Ciência dos Materiais, Instituto Militar de Engenharia, 2005.

Artigo recebido em 03/10/2005 e aprovado em 30/12/2005.

\title{
$\star * * * * *$
}

\section{REM - Revista Escola de Minas 70 anos divulgando CIÊNCIA.}

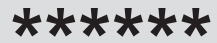 \\ REM: a mais antiga revista técnico- \\ científica do setor mínero-metalúrgico.
}

\author{
$* * * * * *$ \\ www.rem.com.br
}

